Supplement of The Cryosphere, 10, 1021-1038, 2016

http://www.the-cryosphere.net/10/1021/2016/

doi:10.5194/tc-10-1021-2016-supplement

(C) Author(s) 2016. CC Attribution 3.0 License.

(c) (1)

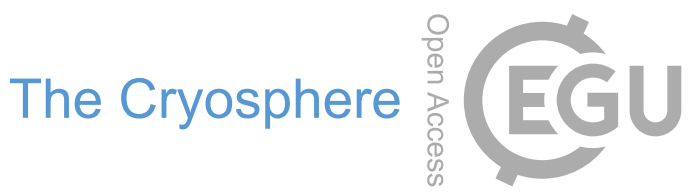

Supplement of

\title{
On the assimilation of optical reflectances and snow depth observations into a detailed snowpack model
}

Luc Charrois et al.

Correspondence to: Luc Charrois (luc.charrois@meteo.fr)

The copyright of individual parts of the supplement might differ from the CC-BY 3.0 licence. 


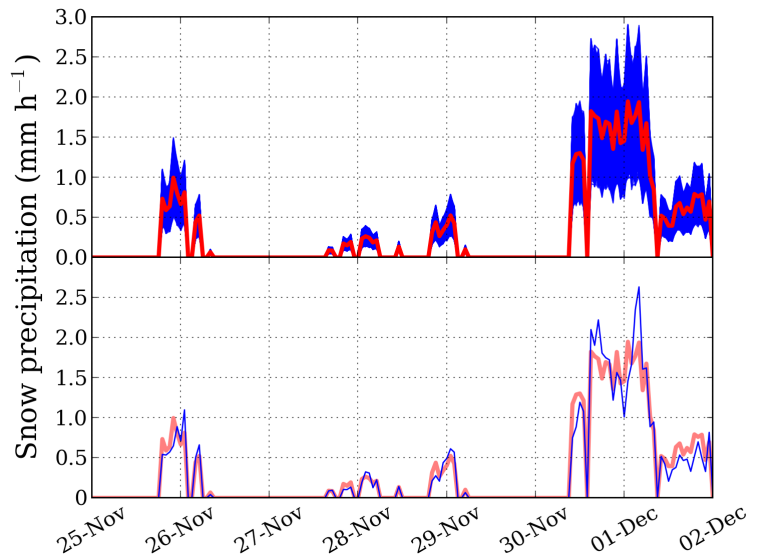

Figure S1: Snow precipitation rate at the CdP site over one week $(25 / 11 / 2010$ to $02 / 12 / 2010$ ), from the unperturbed meteorological reanalysis (in red, both top and bottom), a single realization of the perturbed reanalysis (in blue, bottom), and the full ensemble of 300 perturbed analysis (in blue, top).

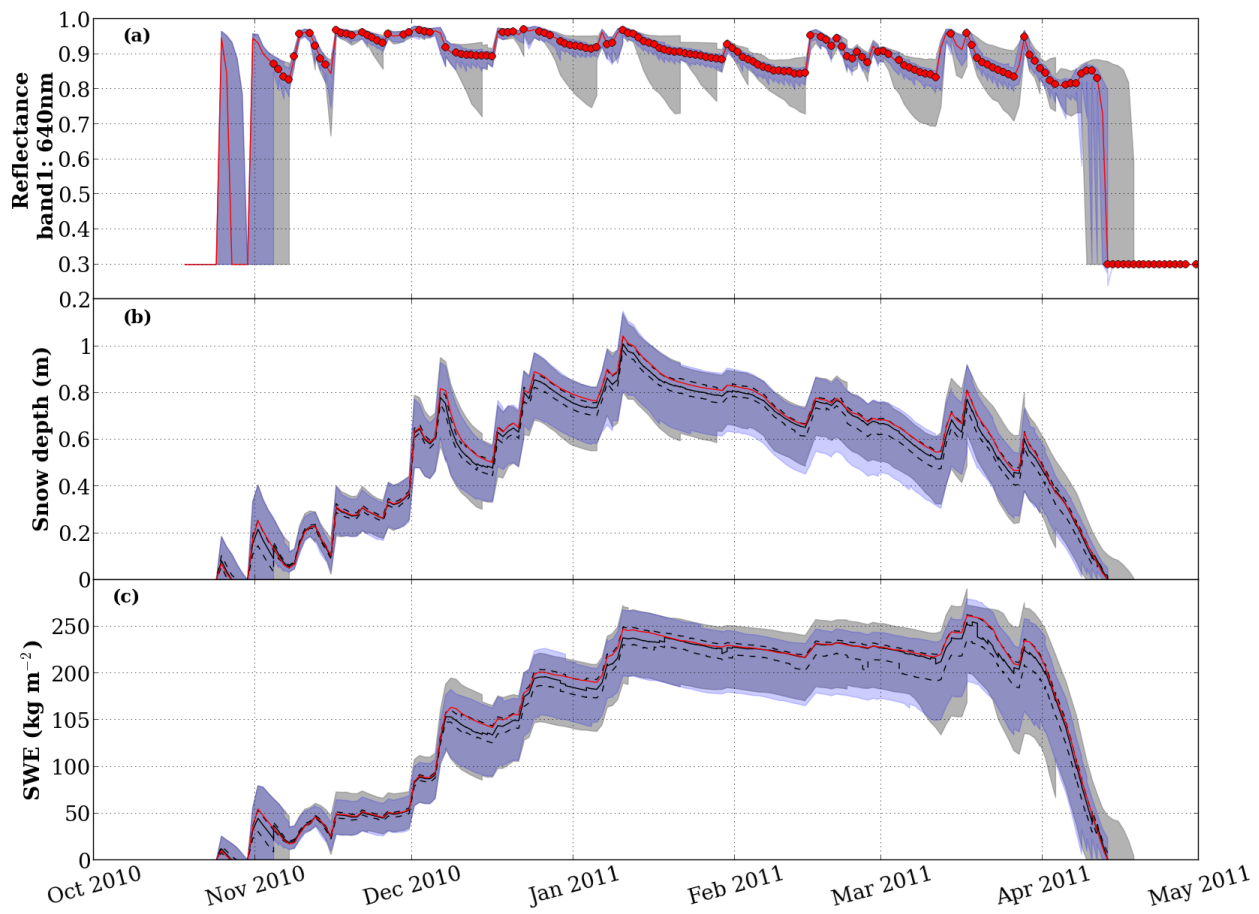

Figure S2: Same as Fig. 3, but without the 1240-nm reflectance (panel (b) of Fig. 3, and where the grey envelops are from the baseline assimilation experiment and the blue envelops represent the ensemble assimilating MODISlike reflectances every day. The blue color is darker where both envelops are superposed. 


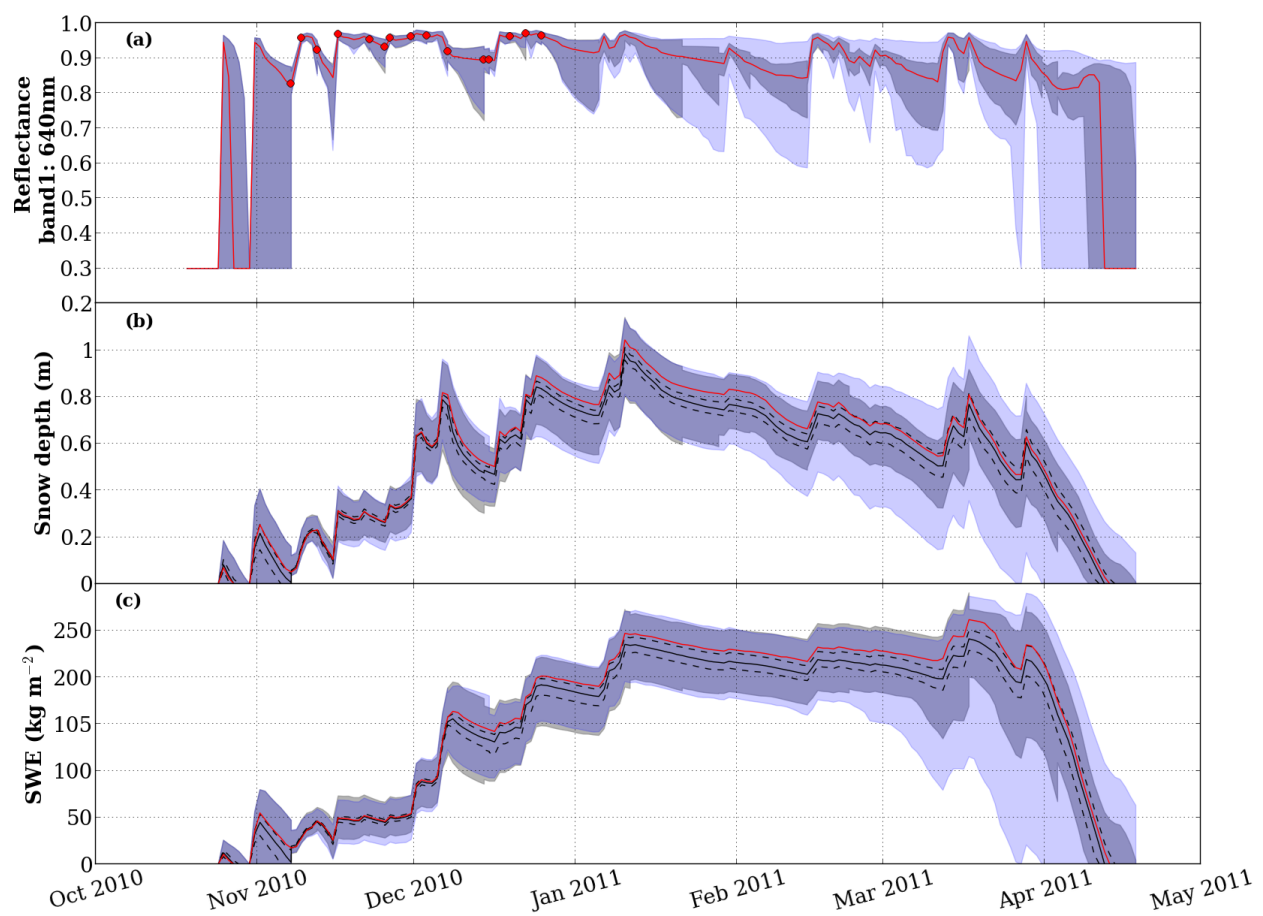

Figure S3: Same as Fig. S2 where the blue envelops are from the experiment assimilating MODIS-like reflectances from October to December 2010 only. 


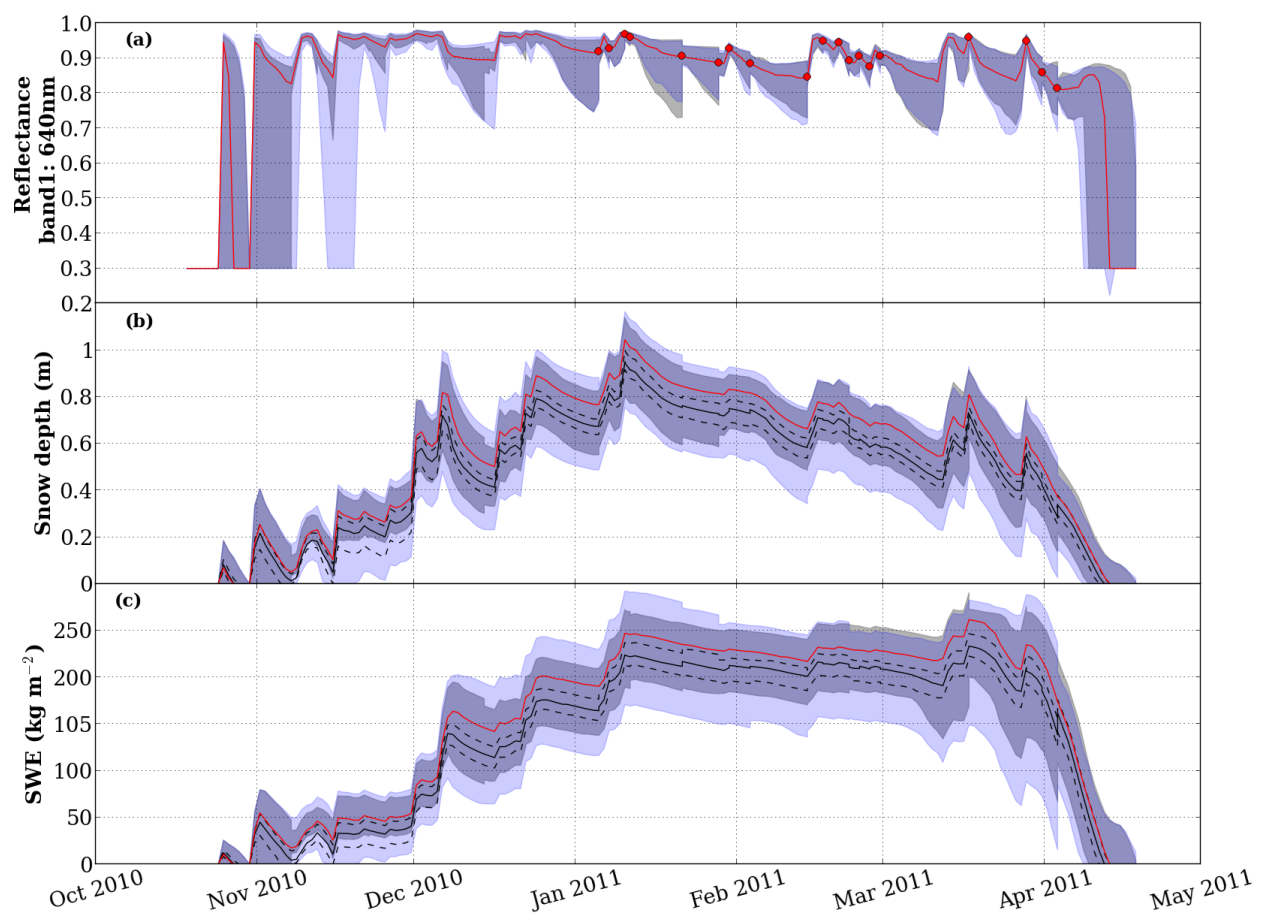

Figure S4: Same as Fig. S2 where the blue envelops are from the experiment assimilating MODIS-like reflectances from January to April 2011 only. 


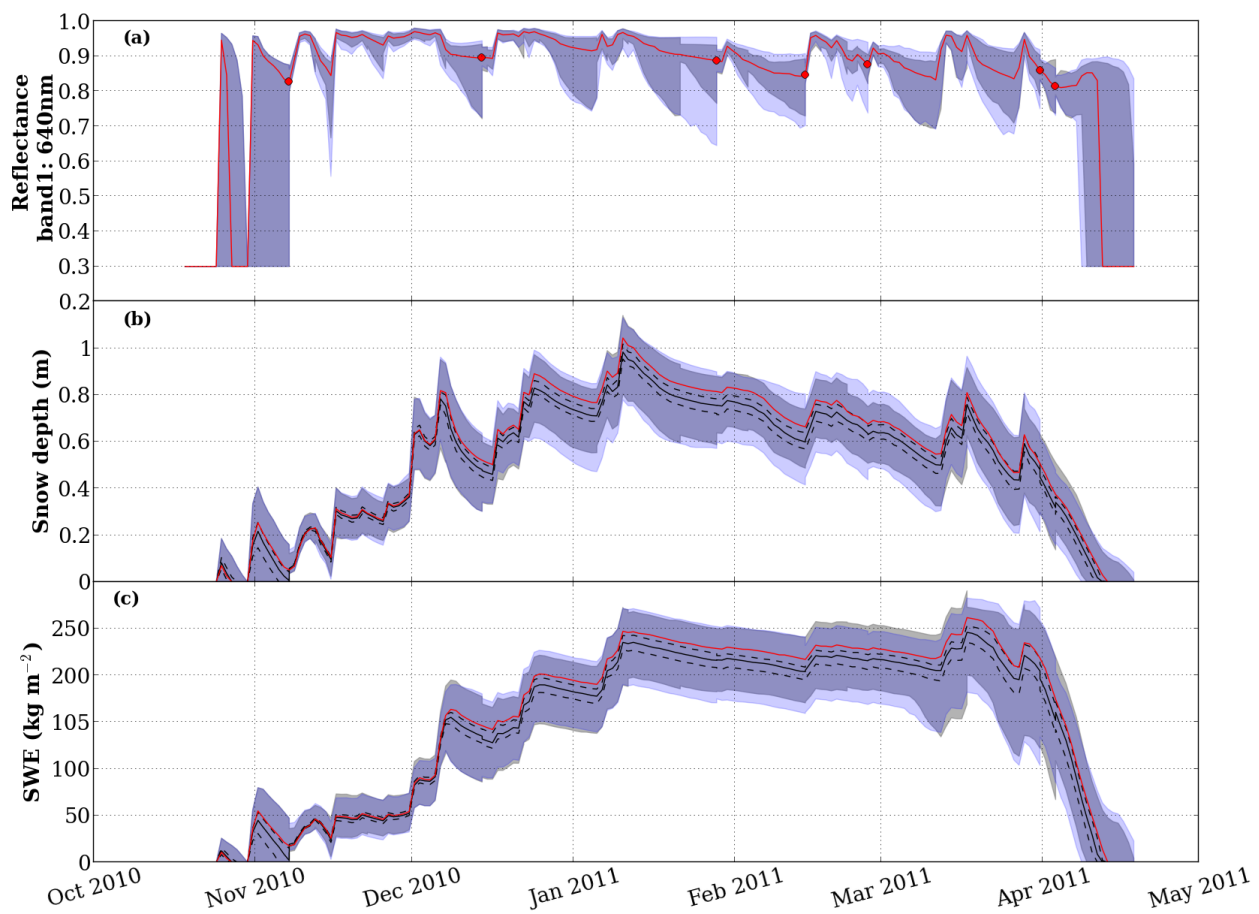

Figure S5: Same as Fig. S2 where the blue envelops are from the experiment assimilating MODIS-like reflectances at 7 selected dates right after several daylong periods without precipitations and right before snowfalls. 


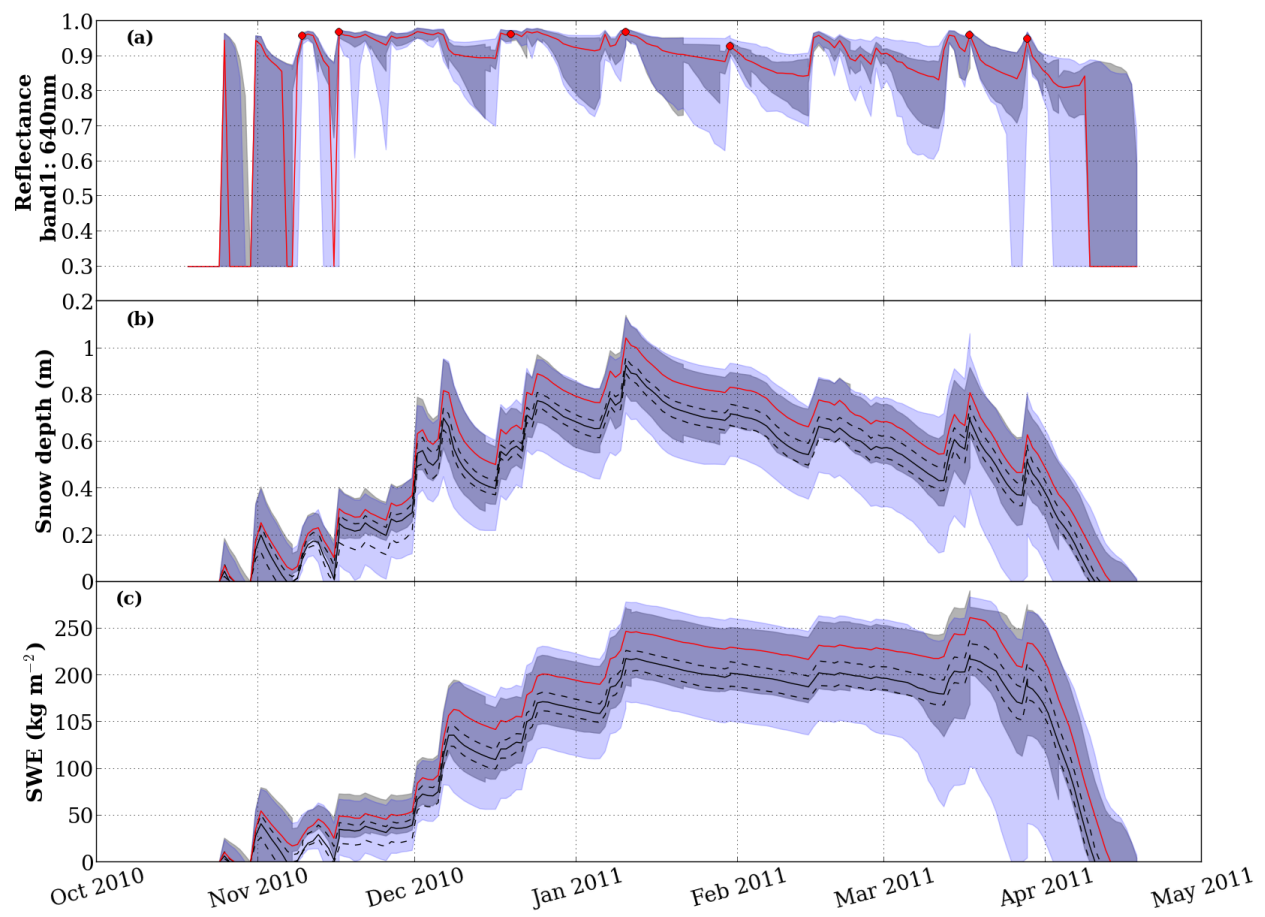

Figure S6: Same as Fig. S2 where the blue envelops are from the experiment assimilating MODIS-like reflectances at 7 selected dates right after snowfall events. 


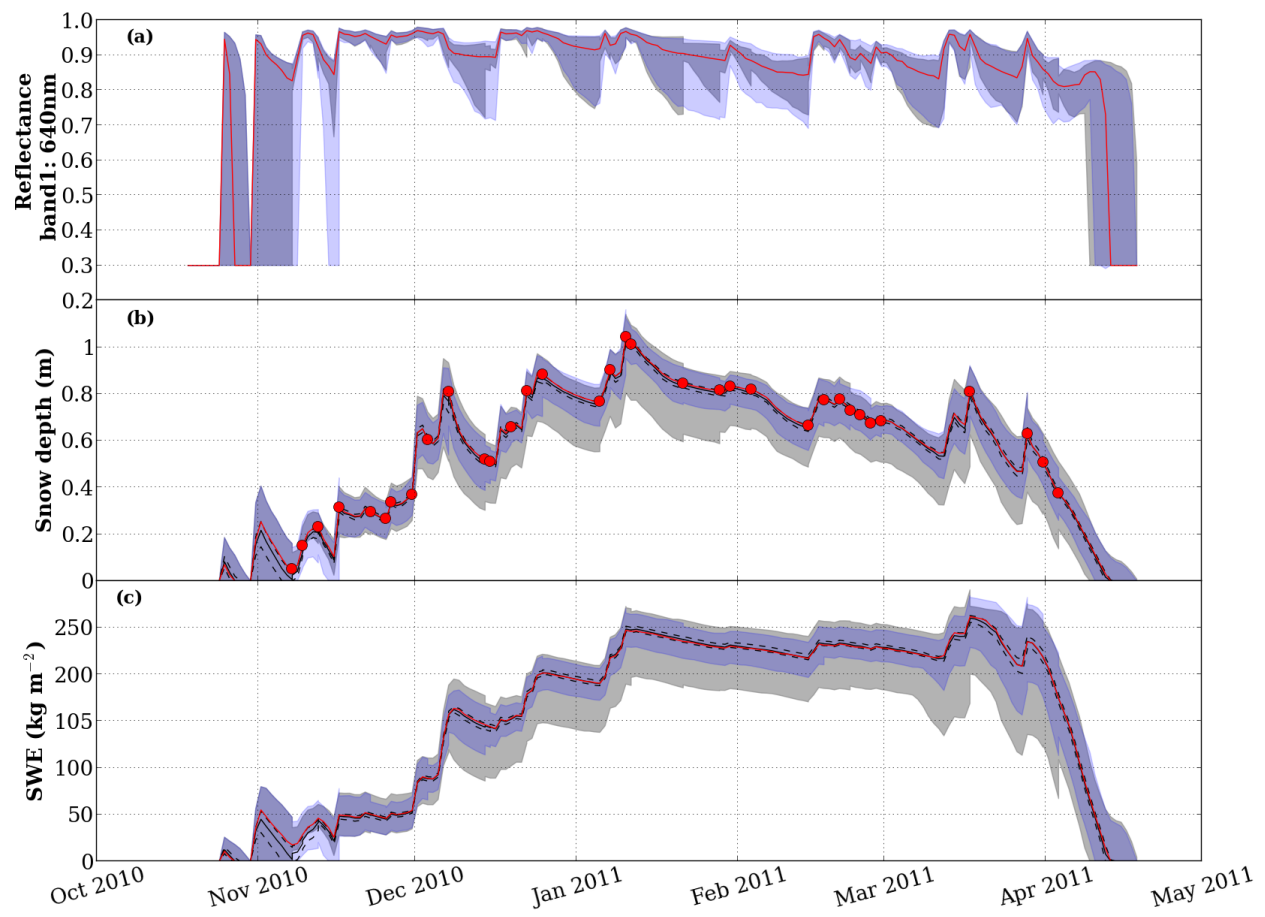

Figure S7: Same as Fig. S2 where the blue envelops are from the experiment assimilating synthetic SD observations with the same time frequency as MODISlike reflectances in the baseline experiment. On graph (b), the red dots show the assimilated SD observations. 


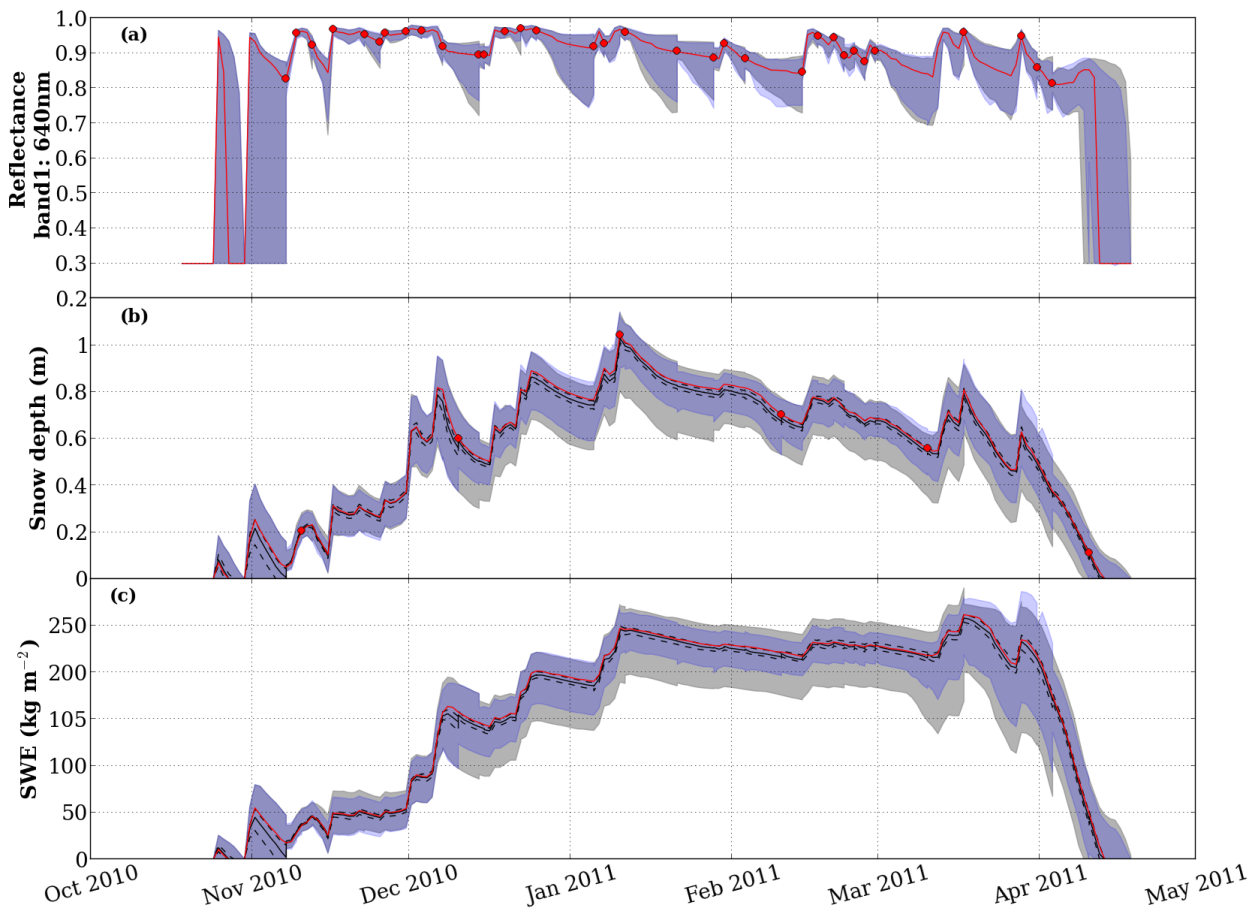

Figure S8: Same as Fig. S2 where the blue envelops are from the experiment assimilating jointly synthetic MODIS-like reflectances and synthetic SD observations. The MODIS-like reflectances are assimilated with the same time frequency as MODIS-like reflectances in the baseline experiment while synthetic SD observations are assimilated the 10th of each months. On graph (a) and (b), the red dots show the assimilated MODIS-like reflectances and SD observations, respectively. 